\title{
How Creative are the Super-Rich?
}

\section{Jason Potts}

7 This paper seeks to analyse the contribution of the 'creative industries' to the ranks of the super-rich. Rich list 2005-6 data for Australia and several other countries, indicate that while the creative industries represent only a small share of aggregate income (about five per cent) and an even smaller share of the largest national and global companies, they are disproportionately represented as generators of extreme personal wealth (about 10 per cent) and even more-so for the young rich (approximately one-third). Young fortunes are the stand-out feature of the creative industries from this perspective, and a tangible sign of their economic significance in both an open economy and an open society. The paper seeks to explain, from the evolutionary economic perspective, what this empirical finding might mean for public policy.

\section{Creative Industries}

The concept of creative industries originates from a disparate group of economists, economic geographers and cultural and media studies academics who have sought to unify the theories of economic, regional and cultural growth into a single opensystem analytic framework (Caves, 2000; Howkins, 2001; Florida, 2002; Hartley, 2005; Garnham, 2005; Cunningham, 2004; 2006). The creative industries are therein defined as the set of industries that have their 'origin in individual creativity, skill and talent, and which have a potential for wealth and job creation through the generation and exploitation of intellectual property' (Department of Culture, Media and Sport, 2001). This definition is still somewhat unsettled, but typically includes the Standard Industrial Classifications of: architecture, advertising, art, crafts, design, fashion, film, music, performing arts, publishing, research and development, software, toys and games, TV and video games. The creative industries are defined by a common input — creativity — and a common output - novel content or intellectual property.

Many elements of this classification have been around for a long time. What is interesting about them now, however, is that they seem to be experiencing a profound change in economic significance due to the confluence of widespread adoption of digital technologies, high levels of mass education, and easier access to global information and markets. Recent analysis for the UK, for example, estimates the growth rate of real value added of the creative industries sector at about six per cent, which is twice the growth rate of the aggregate economy (Department of Culture, Media and Sport, 2006).

Jason Potts is Senior Research Fellow, ARC Centre of Excellence for Creative Industries and Innovation, Queensland University of Technology, and Senior Lecturer, School of Economics, University of Queensland. 
Yet just as interesting from an evolutionary perspective is the relative performance of creative industries entrepreneurs in rich lists, and the implications this has for understanding the growing significance of this composite sector. It is hoped that the unpacking of the sectoral composition of the upper extreme of personal wealth, will help to better explain the dynamic economic and policy significance of the creative industries, not just to static welfare, which has been the mandate of cultural economics (for example, Throsby, 1994, 2006), but as a driver of economic growth and transformation (Cowan, 2002; Cunningham, 2006; Potts, 2006).

The creative industries are tricky to analyse with normal economic data, as they cut across standard industry classifications (Creative Industries Research and Applications Centre, 2004). As with all of the service sector, aggregate labour productivity, for example, is difficult to measure in this sector, and with the exception of huge media companies, creative industries companies tend to be small and fast changing in structure and size (De Vany, 2004). Furthermore, the creative industries tend to be highly concentrated in major global cities due to the benefits of a concentration of creative talent and elite consumers, making them significant drivers of urban development independent of the location of big firms (Florida, 2002). Moreover, creative industries' products are not so much massproduced as mass-accessed (often at negligible marginal cost) as their outputs are by definition sui generis (Rifkin, 2000; Caves, 2000).

For example, a creative industries producer such as pop star Madonna earns significant Schumpeterian profits from a portfolio of monopoly rents created with very little physical capital in a highly competitive industry. Madonna is not a global corporation, nor a timeless industrial sector, and it is unlikely she directly employs more than a handful of people. Yet like the Beatles before her, or the boys from Google or YouTube, she has generated a vast flow of income through creative capital and enterprise. By providing a window into the Schumpeterian profits in an economy as the reward for novelty, rich list data and analysis may help us to better understand how individual creativity can be harnessed to generate new sources of economic value, and extreme wealth in the process.

\section{Economics of Extreme Wealth}

Two explanations of extreme personal wealth are evident in modern economics. For neoclassical economists wealth accrues from rents to either, talent and skill, or from power, exclusion or other market imperfections. The explanation of extreme wealth in neoclassical analysis is therefore logically the same as the explanation of poverty, namely market failure. In evolutionary economics, however, vast wealth is analysed as the result of profit that accrues to the introduction of a valuable new idea into an open economic system; this is the return to entrepreneurship and innovation. Extreme wealth is a function of the extent of the market, and when a good new idea is adopted on a global scale where price is everywhere greater than marginal cost, these profits can be considerable. 
We often think of profits as earned only by firms, with individuals earning wages or rents. But rich list data plainly indicate that the majority of extreme personal wealth is due to profit from entrepreneurship (Siegfried et al, 1995). The aggregate effect of entrepreneurship is the continual transformation or evolution of the economic order. Although this process of innovation occurs throughout the economy on all different scales, it has long been known that it tends to cluster in places, sectors and times about particular new technologies (Schumpeter, 1939; Dopfer and Potts, 2007). Examples of this phenomenon include railways and steel in the late $19^{\text {th }}$ century, radio in the 1930 s, mass-production manufacturing in the 1950s, micro-electronics in the 1960-70s, and finance and banking in the 1980s. These clusters of entrepreneurial activity resulted in a changed relative size and organisation of industries, new firms, and, often, the creation of immense new personal wealth (Freeman and Soete, 1997).

Evolutionary economists tend to analyse this process in relation to differential growth rates of firms or industries (Metcalfe, 1998), but it may also be analysed through the differential accumulation of profit as personal wealth. Yet despite their ubiquity in the business press (where they originate) rich lists have been little used in economic analysis beyond the work of John Siegfried et al (Siegfried and Roberts, 1991; Blitz and Siegfried, 1992; Siegfried and Round, 1994; Hazledine and Seigfreid, 1997) who used rich list data (initially from Money magazine) to identify the origins of concentrations of extreme wealth and to connect this to the study of the market process. Their findings for Australia, the United Kingdom (UK), New Zealand (NZ) and the United States (US) were that, first, about onethird of vast fortunes are inherited and two-thirds self-made, with the self-made proportion steadily increasing over the $20^{\text {th }}$ century. Of the extremely rich, most became so by enterprise rather than inheritance or roguery (see also Atkinson and Harrison, 1978; Kopczuk and Saez, 2004; Schneider, 2004; Atkinson and Leigh, 2005).

Second, fortunes are broadly distributed across all sectors of the economy, but with shifting concentrations (see also Rubenstein, 1981). In the 1800s, for example, vast Australian fortunes were concentrated among pastoralists and merchants (see Rubinstein 2004; Leigh 2005). Yet by 1958 these fortunes were disproportionately concentrated in manufacturing and by 1990 the concentration had shifted to financial services (Siegfried et al, 1995). This is prima facie evidence for economic evolution as an ongoing process of structural transformation through the emergence and growth of new industries and the induced decline in significance of other industries. Indeed, casual inspection of any rich list will often reveal people integral to the founding of a new industry or the creation of a new mass market (for example, Henry Ford, Steve Jobs, Rupert Murdoch).

Third, and most importantly, approximately three-quarters of large fortunes originate in competitive (and often highly competitive) industries. Siegfried et al 
(1995:285) attribute this to the normal working of the competitive process, noting that

a good number of the great fortunes in the world have accrued to individuals who first recognized an opportunity. Many of the competitive entrepreneurial fortunes fit the Schumpeterian characterisation of competition as a process of creative destruction, with new products replacing old ones. These are essentially disequilibrium fortunes.

By offering an analysis of the extreme tail of the income distribution, rich lists shed light on the processes of growth and development.

\section{Data and Classification}

Several rich lists were analysed. For Australia, the lists used are: the Business Review Weekly top 500 public and private companies in 2005; the richest 200 individuals and families in 2005; and the young rich (top 100 aged 40 and under) for 2004 and 2006. New Zealand data come from National Business Review for 2005 (cut-off $\$ 15$ million). For the UK, the data come from the Sunday Times richest 500 for 2005 (minimum $£ 100$ million) and the young rich list for 2006 (compiled for the richest 100 aged 30 and under). For the US, the data come from the Forbes 400 for 2006 (beginning at $\$ 900$ million). Global company data was derived from the Forbes 2000 for 2006, and young billionaires were derived from Forbes lists for 2006. Note that no young rich data are available for the US and NZ. Except for the company lists, the figures presented are shares (not count data, although these produce similar results) of the percentage of wealth held by creative industries entrepreneurs over the population of the entire list, with inherited fortunes excluded.

Rich lists are compiled by business magazines though subcontracted research organisations (IbisWorld, Reuters, Bloomberg, Exshare, Thomson IBES, FT data, et $a l)$ and are constructed from public records and business intelligence (including interviews). There are two main limitations of rich lists. First, they are biased toward new fortunes in single businesses and against more diffuse holdings (as for example over an extended family). Second, they tend to underestimate the extent of distributed or concealed wealth. However, these problems are mostly in the realm of inherited fortunes, which are excluded from our analysis. Despite these limitations, rich lists are widely acknowledged to be sufficiently complete for comparative analysis (Siegfried and Round, 1994; Gilding, 1999; Stilwell and Ansari, 2004).

Yet the main problem with rich lists for this analysis, however, is that 'creative industries' is a new and somewhat unsettled classification (compare, for example, Caves, 2000; Howkins, 2001; and Florida, 2002) that does not conform neatly to the Standard Industrial Classifications system, nor to the truncated classifications the magazines and newspapers tend to use. The rich lists must 
therefore be re-interpreted as follows. The creative industries are not identical to the 'cultural industries', or to the 'cultural and recreational services' classification standard in rich lists. We exclude all sports as they rely on skill, not creativity, casinos and racing (luck not creativity), and tourism and heritage wealth (physical or cultural asset, not creativity). From the software and technology category, we exclude all infrastructure and hardware, but include the design contribution to consumer applications (that is, engineering for human-product systems, not just engineering a technical system). From the 'media' category, we exclude all infrastructure providers and include only content providers. Printers are excluded but publishers are in. Retail with substantial design aspects are included (for example, fashion companies), but most retail is excluded (for example, supermarkets). Entertainers are included (for example, actors, musicians), but sports stars (who make their money through media) are excluded. Although undeniably creative in some measure, we do not include financial, insurance or banking companies, or business consultants and services. This transformation and re-classification of the rich lists was performed through individual inspection of the companies or individuals through the profiles provided by the magazines and through further research based on company websites.

\section{Results}

The creative industries' share of GDP, of the largest companies, of all personal fortunes and of the young rich is summarized in Table 1 below.

Table 1: Creative Industry Shares

\begin{tabular}{|c|c|c|c|c|}
\hline Country & Economy & Largest Firms & All Rich & Young Rich \\
\hline Australia & $4.5-6 \%$ & $3.7 \%$ (by count) & $\begin{array}{c}9.0 \% \\
\text { (8.5\% by count) }\end{array}$ & $\begin{array}{c}35.4 \% \\
\text { (37-37.5\% by count) }\end{array}$ \\
\hline$N Z$ & $3.1 \%$ & - & $\begin{array}{c}9.1 \% \\
\text { (9.5\% by count) }\end{array}$ & NA \\
\hline$U K$ & $7.9 \%$ & - & $\begin{array}{c}12.9 \% \\
\text { (12.6\% by count) }\end{array}$ & $\begin{array}{c}36 \% \\
\text { (33\% by count) }\end{array}$ \\
\hline USA & $\begin{array}{c}2.4 \% \\
\text { (cultural industries) }\end{array}$ & - & $\begin{array}{c}14.2 \% \\
(12.5 \% \text { by count })\end{array}$ & NA \\
\hline World & $4 \%$ & $3.5 \%$ (by count) & $\begin{array}{c}25.0 \% \\
\text { (24\% by count) }\end{array}$ & $\begin{array}{c}39 \% \\
\text { (37\% by count) }\end{array}$ \\
\hline
\end{tabular}


The share of the creative industries as a proportion of GDP provides our benchmark for comparing the proportion of creative industries in the rich lists. These estimates lie between 2.4-7.9 per cent with the differences due to both the different relative sizes of creative industries and also to different definitions. The $\mathrm{NZ}$ and US estimates are defined so as to exclude software, R\&D, advertising, games and architecture. This is a significant exclusion for the US, yet no comparable figures to the Australian and UK estimates currently exists (cf. Florida, 2002). The 4.5 per cent figure for Australia represents the Department of Culture, Media and Sport classification by sector. The higher figure of six per cent share of GDP for Australia includes both the creative industries themselves and creative workers embedded in other sectors (for example, graphic designers or writers working for banks). The UK estimate of 7.9 per cent is similarly composed. Each of these figures was compiled by a research agency associated with the creative industries in the respective country and is presented here only for comparison with the rich list data.

We first consider large companies. The Forbes 2000 is a global list compiled as a composite index. There were 75 creative industries firms in the top 2000 (3.75 per cent), 51 of which were media companies, 19 in software and just five collectively in design (Swatch), fashion (Christian Dior, Ralph Lauren), publishing (Elsevier) and games (Electronic Arts). By any account, the creative industries are not significantly represented in the world's biggest businesses. As something of an aside, note that 15.5 per cent of the Forbes 2000 companies can nevertheless be considered significant users of creative industries services such as design, fashion and advertising in the development and sale of products. Obviously, only a fraction of the value created by these companies can be attributed to this input.

While almost an order of magnitude shorter than the global list, the same pattern is observed in both public and private Australian firms. For 2006 there were just seven creative industries among the top 500 private companies, and of the top 500 public companies 30 were in creative industries (six per cent), and half of these were media companies. However, the count of embedded creative industries (CI) companies or companies that contract-in CI services was only 25 (five per cent). This is significantly lower than in the global 2000 list because of the lower proportion of manufacturing and retail companies among the biggest Australian private companies.

Of the 200 richest Australians in 2006, 59 were in property; 29 in retail; 16 in manufacturing; 11 in resources; nine in media (including four billionaires); six in software and technology, and three in entertainment. Excluding one software and technology company as an Internet Service Provider yields a creative industries count of 17 , equating to a nine per cent share of the total wealth held by these individuals.

Of the 222 richest New Zealanders in 200521 were in the creative industries (including six in software, and all under 40), collectively holding 9.1 per cent of the total listed wealth. Entertainment and the arts accounted for over half (11) of the creative entrepreneurs, which is unusually high, and it is also worth noting that 
there were no publishing or network media fortunes. The New Zealand rich list has proportionately more content providers than aggregators as compared to Australia.

The Sunday Times rich list of the 500 richest Britons for 2005 contains 63 creative industries entrants, representing 12.9 per cent of the total list wealth. This figure is somewhat differently composed to both the Australian, global and US distribution, with a significant portion of individual musicians, actors and entertainers. It also contains the only advertising fortune yet observed (Saatchi). A large number of publishing and fashion fortunes are evident in this list (29 per cent of the CI list), but relatively few software and technology fortunes (just under 10 per cent of the CI list).

Of the Forbes 400 richest Americans in 2006, 50 are in the creative industries (12.5 per cent by count, 14.2 per cent by share of wealth). The distribution of creative industries fortunes is heavily skewed toward the top 100 of which 24 per cent are creative industries fortunes. This skew is greater than we observe in Australia and broadly reflects the enormous cultural and media empires and exports associated with Hollywood, as well as television stars (for example, Oprah Winfrey, Martha Stewart) and the significant presence of young software billionaires (the owners of companies such as Yahoo, Google, and eBay).

Interestingly, the global rich list of the top 100 personal fortunes (Forbes), of which entry to the list begins at US\$6 billion, comprises 24 per cent creative industries by count and 25 per cent by share, and is almost exclusively comprised of software and media fortunes. However for the top 500 this falls to 15 per cent by count, which can be attributed to the effect of multigenerational 'old economy' fortunes reasserting themselves. Nevertheless, this plainly signals the global significance of the creative industries to the composition of the new economic order.

\section{Creative Industries and the Young Rich}

In the past few years, rich list providers have begun to track a separate list of young rich aged 40 and under. As one would expect, the young list has a lower minimum wealth and ends well below the top of the 'adult' list. Although the lists share important similarities - both have about the same ratio of inherited to selfmade wealth and the same range over all industries - the notable difference is in the distribution within those industries. In essence, the young rich are much more significantly drawn from the creative industries than their adult brethren.

First, consider the list of the world's billionaires aged 40 and under according to Forbes. There were 46, of which 19 inherited wealth, leaving 27 self-made. Of the 27, eight were young Russians obtaining fortunes in metals and oil (30 per cent). Of the remainder, two fortunes came from finance, two from retail, three from online gambling, four from core CI (including JK Rowling), six from software (including eBay, Yahoo and Google) which are among a total of 10 based around the internet, with the remainder from transport and manufacturing. The implication is that 39 per cent of the total self-made wealth of the world's 
young billionaires originated in the creative industries. Beyond hopes of spectacular inheritance or going boldly into Russian primary industries (together 59 per cent of origin), the creative industries are the best launching platform to a fast billion or so - next best is gambling and finance.

The $B R W$ Australian young rich list compiles only self-made wealth and contains no billionaires. The wealth of the top 100 individuals for 2006 ranged from \$12 million to \$260 million. Retail, technology, services, entertainment, sport and media account for 78 per cent of young fortunes, with only 18 per cent from manufacturing, resources, or property. This is the inverse of what we observe in both the largest public and private companies, as well as in the industry distribution of the adult rich. Sports stars accounted for 10 per cent of the young rich and are not included in the creative industries, but nine per cent were entertainers, 10 per cent developed new software, 11 per cent were in fashion or design and six per cent were in new media. Overall, 37 per cent made their fortune in the creative industries. This wealth sums to a total creative industries wealth of $\$ 1.52$ billion from $\$ 4.3$ billion (35 per cent). The 2004 young rich list in Australia was very similar, with 37.5 per cent of total list wealth generated in the creative industries.

The Sunday Times young rich list for 2006 was compiled with a cut-off of age 30 or less, and so has less trading companies (and a notable absence of software and technology) and a preponderance of music, fashion and film wealth. Sports stars were excluded (28 per cent of the list), but creative industries additionally represented a 36 per cent share of top 100 wealth.

In sum, for 2005-6 the economic significance of the creative industries by aggregate employment and income is about five per cent. However, as a source of extreme personal wealth in nations this figure rises to about 10 per cent. These fortunes overwhelmingly originated in competitive industries and were often associated with the development of new market niches. This view from the tail clearly indicates that the creative industries are significant generators of new wealth. However, the most striking observation is the much greater significance of the CIs to 'young wealth' as compared to 'old wealth'. One in three young Australian and UK fortunes originated in the creative industries, compared with one in ten for the 'adult' lists.

\section{What Will they Get-up to Next?}

Why is this happening? One reason is that the barriers to entry in the creative industries are much lower than in other sectors, as most of the capital required is carried as talent and imagination, or, as economists like to say, as 'human capital'. A second reason is that creative industry entrepreneurs and artists can tap into global financial and consumer markets with more ease now than in the past. Indeed, well over half of the Australian young rich appear to have made their fortune in global markets. This is the same pattern observed in other countries (for example, US, UK, NZ) that share an institutional framework that promotes creative enterprise on a level playing field (Cowan, 2002). It is certainly not 
unreasonable to evaluate the success of such a system by its ability to generate extreme personal wealth, and by this measure the Australian system is clearly working.

The difference in age profiles in the concentration of creative fortunes highlights an interesting observation on the modern origins of new wealth. In the past, great fortunes came from resources and manufacturing. But there has been a recent and profound shift in the creation of value from engineering things to engineering information (Leadbeater, 2000; Florida, 2002). The creative industries fortunes are in the space of media, fashion, software and design and about the provision of content to the solution of problems. It is already wellknown that the creative industries are growing faster in aggregate than the economy-wide average (as part of the general rise of the service sector). To this can be added the further observation that the extremes of wealth in this sector are leading the charge through the design of new businesses to connect new technologies to new markets. This is the 'creative edge' of the evolutionary transformation of the economic order.

Yet modern analysis of economic change is almost entirely based on the concept of 'economic significance' as represented by aggregate measures of the income, exports or employment that a particular industry generates. This method is applied to both mature industries (for example, broad-acres agriculture, auto manufacture, leisure tourism) and new industries (for example, wine, avionics, digital games) to generate a distribution of public policy attention appropriate to the varying degrees of economic significance so found. Big or prominent industries get more attention, small or diffuse industries get less. This is of course a sensible method for calibrating industry, trade, innovation or competition policy to an economy in equilibrium, yet it can be seriously misleading when applied to a context in which new industries are continually emerging and extant industries are continually transforming as new technologies are differentially adopted and the boundaries between industries themselves become less distinct (Baumol, 2002). For example, digitisation is transforming design from a subcomponent of manufacturing firms into an industry in its own right that extends deeply into the service sector (Creative Industries Research and Applications Centre, 2005), yet design does not figure in any of the industry development policies currently in place at the State or Federal level in Australia.

The arrival of new industries and sources of economic value that drive continual endogenous transformation signals economic evolution, which is an entirely normal process in a modern market economy. From the open system perspective, public policy must therefore seek to continually monitor and adapt to the ever-changing profiles of income, exports and employment that economic evolution engenders. But to provide this sort of analysis, we must consider not just the aggregate averages of industry significance, but also the changing signals of emerging significance that derive from the tails of the distributions.

The study of the extreme rich in the context of creative industries highlights a classification problem that bedevils cultural, media, industry and competition policy, namely the social value of creativity. When viewed as cultural industries, 
there is a well-worn argument that creative endeavours warrant public subsidy. Yet when re-conceptualized as the creative industries, we find an escalator to personal wealth. Did the creative industries throw up so many young rich because of policy planning or in spite of it? Australia's creative rich certainly may have benefited from public support of and merit based access to acting academies and universities, for example, and the relative ease of starting companies, hiring staff and protecting intellectual property is probably not insignificant to the creation of media and software fortunes.

Yet there is little evidence for a catalytic role played by industry or cultural policy in generating these fortunes. Indeed, it could be said that the recent rise of creative enterprise as a legitimate source of economic value and significant personal wealth has taken policy makers in these domains somewhat by surprise (Cunningham 2006). The public policy attention that has been focused on the creative industries arose largely due to monitoring of average or aggregate measures, such as employment or trade figures, that are necessarily post hoc and therefore attain significance only after the early phases of industrial evolution have passed (see Ross, 2006-7). Closer monitoring of not just relative growth rates but also new fortunes might have helped policy makers keep pace with industrial transformation in something at least closer to real time. While it is not the purpose of government to render great fortunes for a handful of individuals, it is surely the job of policy to set the conditions for wealth creation through enterprise as widely as possible, by avoiding presumptions about the sectors or industries from which these structural developments may arise. Analysis of rich lists can help here, by providing a window into the ever shifting space of opportunity that new technologies and markets bring.

Political economists are sometimes wont to view rich lists as static emblems of the social injustice of a market economy. But rich lists are interesting not because of the power structures they ostensibly represent - for they are transitory, disequilibrium phenomena - but rather for the forward insight they give through the early warning of new fortunes into the evolution of industries and markets. The creative industries, in this view, are not the perpetual subsidy cases of the much maligned cultural industries, but a new and vibrant sector characterized by significant opportunities for rapid and global growth. And so just as the business magazines that publish rich lists ostensibly justify such 'business porn' (that is, the solicitous display of naked wealth) by its educational value to aspiring entrepreneurs, so too may a better economic understanding of the nature and causes of extreme wealth be of educational value to policy makers.

\section{References}

Atkinson, A. and A. Harrison (1978), Distribution of Personal Wealth in Britain, Cambridge University Press, Cambridge.

Atkinson, A. and A. Leigh (2005), 'The Distribution of Top Incomes in Australia and New Zealand’, ANU Discussion Paper No. 514. 
Baumol, W. (2002), The Free-Market Innovation Machine: Analyzing the Growth Miracle of Capitalism, Princeton University Press, Princeton.

Blitz, R. and J. Siegfried (1992), 'How Did the Wealthiest Americans Get So Rich?' Quarterly Review of Economics and Finance 32:5-26.

Caves, R. (2000), Creative Industries: Contracts Between Art and Commerce, Harvard University Press, Cambridge, Ma.

Creative Industries Research and Applications Centre (2004), 'Creative Industries Mapping Document', Queensland University of Technology.

Creative Industries Research and Applications Centre (2005), The Economy of Queensland Design, Queensland University of Technology.

Cowan, T. (2002), Creative Destruction, Princeton University Press, Princeton.

Cunningham, S. (2004), ‘The Creative Industries after Cultural Policy’, International Journal of Cultural Studies 7:105-15.

Cunningham, S. (2006), 'What Price a Creative Economy?', Platform Papers No. 9, Currency House, Sydney.

Department of Culture, Media and Sport (UK) (2001), 'Creative Industries Mapping Document', HMSO, London.

Department of Culture, Media and Sport (UK) (2006), 'Creative Industries Economic Estimates Statistical Bulletin'.

De Vany, A. (2004), Hollywood Economics, Routledge, London.

Dopfer, K. and J. Potts (2007), The General Theory of Economic Evolution, Routledge, London.

Florida, R. (2002), The Rise of the Creative Class, Basic Books, New York.

Freeman, C. and L. Soete (1997), The Economics of Industrial Innovation, Cambridge University Press, Cambridge.

Garnham, N. (2005), 'From Cultural to Creative Industries: An analysis of the Implications of the "Creative Industries" Approach to Arts and Media Policy Making in the United Kingdom', International Journal of Cultural Policy 11:15-29.

Gilding, M. (1999), 'Superwealth in Australia: Entrepreneurs, Accumulation and the Capitalist Class’ Journal of Sociology 35:169-82.

Hartley, J. (ed) (2005), Creative Industries, Blackwell, Carlton.

Hazledine, T. and J. Siegfried (1997), 'How Did the Wealthiest New Zealanders Get So Rich?’ New Zealand Economic Papers 31:35-47.

Howkins, J. (2001), The Creative Economy, Penguin, London.

Kopczuk, W. and E. Saez (2004), 'Top Wealth Shares in the United States, 1916-2000: Evidence from Estate Tax Returns’ National Tax Journal 57:445-87. 
Leadbeater, C. (2000), Living on Thin Air: The New Economy, Penguin, London.

Leigh, A. (2005), Review of G. Hunt, The Rich List: Wealth and Enterprise in New Zealand 1820-2003 and of W. Rubinstein, The All-Time Australian 200 Rich List, pp. 185-7, Economic Record (June).

Metcalfe, J. (1998), Evolutionary Economics and Creative Destruction, Routledge, London.

Potts, J. (2006), 'Four Models of the Creative Industries' ACCII Working Paper, Queensland University of Technlogy.

Rifkin, J. (2000), The Age of Access, Penguin Business Library, New York.

Ross, A. (2006-7) 'Nice Work if You Can Get It: The Mercurial Career of Creative Industries Policy’, Work Organization, Labour \& Globalisation 1(1):1-19.

Rubenstien, W. (1981), Men of Prosperity, Rutgers University Press, New Jersey.

Rubinstein, W. (2004), The All-Time Australian 200 Rich List, Allen and Unwin, Sydney.

Schneider, M. (2004), The Distribution of Wealth, Edward Elgar, Cheltenham.

Schumpeter, J. (1939), Business Cycles, McGraw-Hill, New York.

Siegfried, J. and A. Roberts (1991), 'How Did the Wealthiest Britons Get so Rich?', Review of Industrial Organization 6:19-32.

Siegfried, J., R. Blitz and D. Round (1995), 'The Limited Role of Market Power in Generating Great Fortunes in Great Britain, the United States and Australia', Journal of Industrial Economics 43:277-86.

Siegfried, J and D. Round (1994), 'How Did the Wealthiest Australians Get so Rich?' Review of Income and Wealth 40:191-204.

Stilwell, F. and M. Ansari (2003), 'Wealthy Australians', Journal of Australian Political Economy 52:143-57.

Throsby, D. (1994), 'The Production and Consumption of the Arts', Journal of Economic Literature 32:1-29.

Throsby, D. (2006), Does Australia Need a Cultural Policy? Platform Papers No. 7, Currency House, Sydney.

The author gratefully acknowledges the helpful suggestions of the editor, two anonymous referees and Kate Morrison. 